\title{
Heart Failure in 3 Patients with Acromegaly: Echocardiographic Assessment
}

\author{
Jiro Aono, Sachihiko Nobuoka, Junzo Nagashima, Seiji Hatano, Akihiro Yoshida, \\ Hiroyasu Ando, Fumihiko Miyake and Masahiro Murayama
}

\begin{abstract}
We evaluated 3 patients with acromegaly who developed heart failure. Heart failure appeared to be due to acromegalic cardiomyopathy in 2 patients who did not have hypertension or evidence of coronary artery disease, and it was possibly due to acromegalic cardiomyopathy combined with familiar hypertrophic cardiomyopathy in 1 patient. The common echocardiographic findings in the present three cases were: 1 ) enlargement of the left atrium, 2) markedly dilated left ventricular cavity with diffuse hypokinesis, 3 ) decrease of indices of the left ventricular systolic function, and 4) no evidence of left ventricular hypertrophy. Echocardiographic findings in acromegaly with congestive heart failure resemble those of idiopathic dilated cardiomyopathy.

(Internal Medicine 37: 599-603, 1998)
\end{abstract}

Key words: acromegalic cardiomyopathy, echocardiography, left ventricular function

\section{Introduction}

Cardiovascular abnormalities in patients with acromegaly have been attributed to coexisting hypertension or coronary artery disease $(1,2)$. However, some patients without hypertension or evidence of coronary artery disease exhibit significant cardiac dysfunction, classified as "acromegalic cardiomyopathy" $(3,4)$. We evaluated 3 patients with acromegaly associated with heart failure with an emphasis on echocardiographic findings.

\section{Case Reports}

\section{Case 1}

A 35-year-old Japanese man visited our hospital due to shortness of breath and palpitations on effort of 1 month duration. He had no history of hyperlipidemia or diabetes mellitus, and his family history was unremarkable. A protuberance of the supraorbital region became apparent at the age of 20 years and cardiomegaly was detected when he was 25 years old. On admission, the third heart sounds were audible on auscultation. A chest X-ray showed an increased cardiothoracic ratio (CTR, 57\%) in association with mild pulmonary congestion. The serum level of growth hormone $(\mathrm{GH})$ was $26 \mathrm{ng} / \mathrm{ml}$ and the serum level of IGF-I was $915 \mathrm{ng} / \mathrm{ml}$. The serum level of total cholesterol was $195 \mathrm{mg} / \mathrm{dl}$ and triglyceride was $166 \mathrm{mg} / \mathrm{dl}$.
Fasting blood glucose (FBS) was $114 \mathrm{mg} / \mathrm{dl}$, and oral glucose tolerance test (GTT) demonstrated a borderline pattern. Thyroid function tests demonstrated normal thyroid function (thyroid-stimulating hormone (TSH): $0.5 \mu \mathrm{U} / \mathrm{ml}$, free $\mathrm{T}_{3}: 4.21 \mathrm{pg} /$ $\mathrm{ml}$, free $\left.\mathrm{T}_{4}: 1.3 \mathrm{ng} / \mathrm{dl}\right)$. The results of cranial computed tomography (CT) suggested the presence of a pituitary adenoma. Magnetic resonance imaging (MRI) showed a localized pituitary adenoma $(9 \times 5 \mathrm{~mm})$. Echocardiography revealed a markedly dilated left atrium and left ventricular cavity with diffuse hypokinesis, the left atrial dimension (LAD) was $48 \mathrm{~mm}$, the diastolic left ventricular dimension (LVDd) $78 \mathrm{~mm}$, the systolic left ventricular dimension (LVDs) $67 \mathrm{~mm}$, \% fractional shortening (FS) $14 \%$, and the left ventricular mass (LVM) calculated by M-mode echocardiography $226 \mathrm{~g}$ (Fig. 1). On pulsed Doppler examination, peak flow velocity at the left ventricular outflow tract (PFV) was decreased to $53 \mathrm{~cm} / \mathrm{sec}$, peak transmitral inflow velocity in the early diastole (E) was $67 \mathrm{~cm} / \mathrm{sec}$, peak transmitral inflow velocity in the atrial systole (A) was $46 \mathrm{~cm} /$ $\mathrm{sec}$, and $\mathrm{A} / \mathrm{E}$ ratio was 0.69 . Cardiac catheterization was performed on hospital day 12. Coronary angiography showed normal coronary arteries. Left ventricular end-diastolic pressure (LVEDP) was $10 \mathrm{mmHg}$, pulmonary arterial pressure (PAP) was $26 / 8 \mathrm{mmHg}$ and mean pulmonary capillary wedge pressure (PAWP) was $11 \mathrm{mmHg}$. A biopsy of the right ventricle obtained via cardiac catheterization revealed hypertrophic and loosely associated cardiac muscle fibers and diffuse interstitial

From the Second Department of Internal Medicine, St. Marianna University School of Medicine, Kanagawa

Received for publication March 10, 1997; Accepted for publication March 24, 1998

Reprint requests should be addressed to Dr. Jiro Aono, the Second Department of Internal Medicine, St. Marianna University School of Medicine, 2-16-1 Sugao, Miyamae-ku, Kawasaki 216-8511 

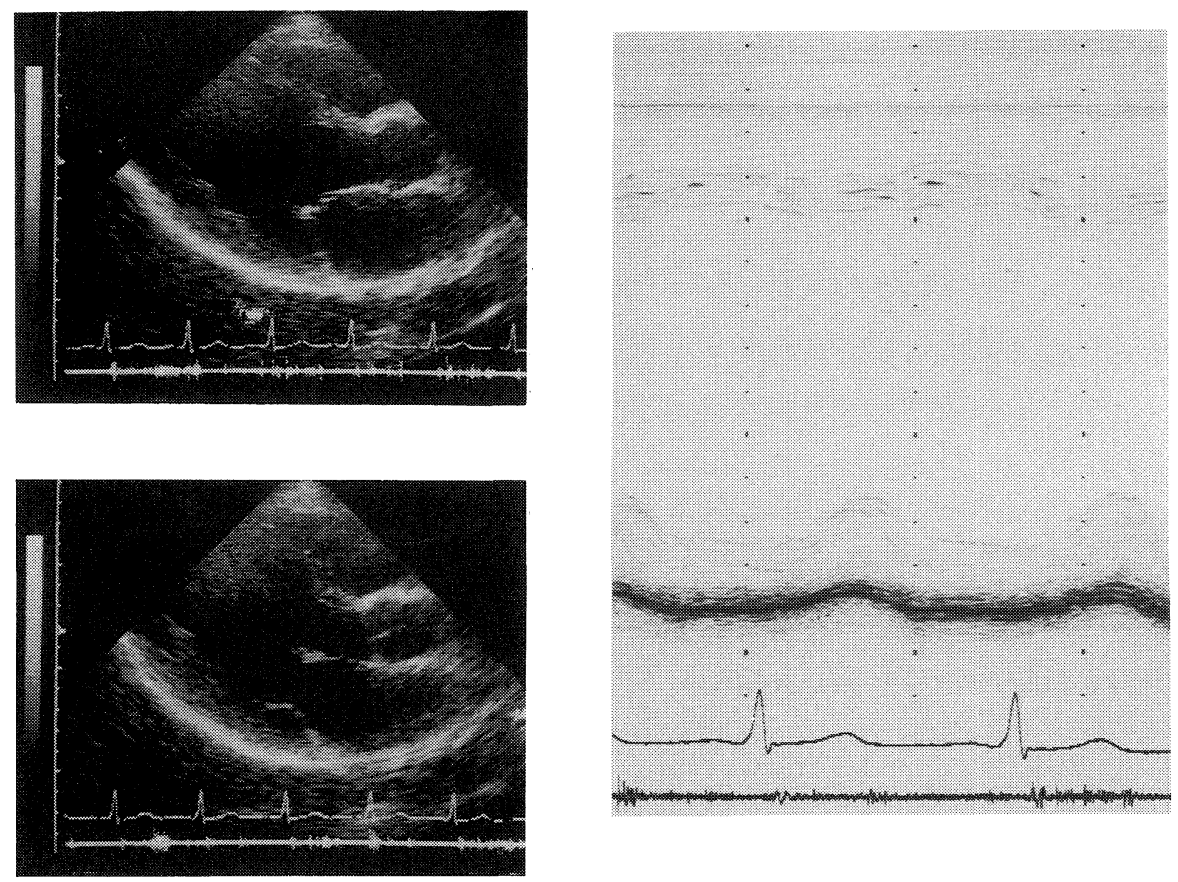

Figure 1. Echocardiographic findings in case 1.

fibrosis (Fig. 2). Treatment with diuretics and angiotensin converting enzyme inhibitor (ACE-I) resulted in an improvement of pulmonary congestion and a disappearance of cardiac symptoms.

\section{Case 2}

A 58-year-old Japanese man was admitted to our hospital for removal of a pituitary adenoma. He had no history of diabetes mellitus or hyperthyroidism, and his family history was unremarkable. Bitemporal hemianopsia and an acromegalic appearance were noted when he was 47 years old. He has experienced exertional dyspnea since the age of 55 . On admission, a chest Xray showed a CTR of $51 \%$. The serum level of total cholesterol was $144 \mathrm{mg} / \mathrm{dl}$ and triglyceride was $132 \mathrm{mg} / \mathrm{dl}$. GTT was not performed, FBS was $94 \mathrm{mg} / \mathrm{dl}$ and glycated hemoglobin (HbA1c) was $5.5 \%$. Serum levels of GH and IGF-I were $87 \mathrm{ng} / \mathrm{ml}$ and $1,610 \mathrm{ng} / \mathrm{ml}$, respectively. Echocardiography revealed a moderately dilated ventricular cavity with diffuse hypokinesis. Echocardiographic parameters were as follows: LAD: $38 \mathrm{~mm}$, LVDd: 67 mm, LVDs: 54 mm, FS: 19\%, and LVM: 206 g (Fig. 3). On pulsed Doppler examination, PFV was decreased to 51 $\mathrm{cm} / \mathrm{sec}$, E was $36 \mathrm{~cm} / \mathrm{sec}$, A was $60 \mathrm{~cm} / \mathrm{sec}$, and A/E ratio was 1.67. Coronary angiography performed on hospital day 10 revealed normal coronary arteries. LVEDP was $12 \mathrm{mmHg}$, PAP was $26 / 5 \mathrm{mmHg}$ and mean PAWP was $12 \mathrm{mmHg}$. Treatment of a few days of administration of diuretics resulted in a disappearance of cardiac symptoms. The patient underwent transsphenoidal surgery on hospital day 21 .

\section{Case 3}

A 58-year-old Japanese man was admitted to our hospital

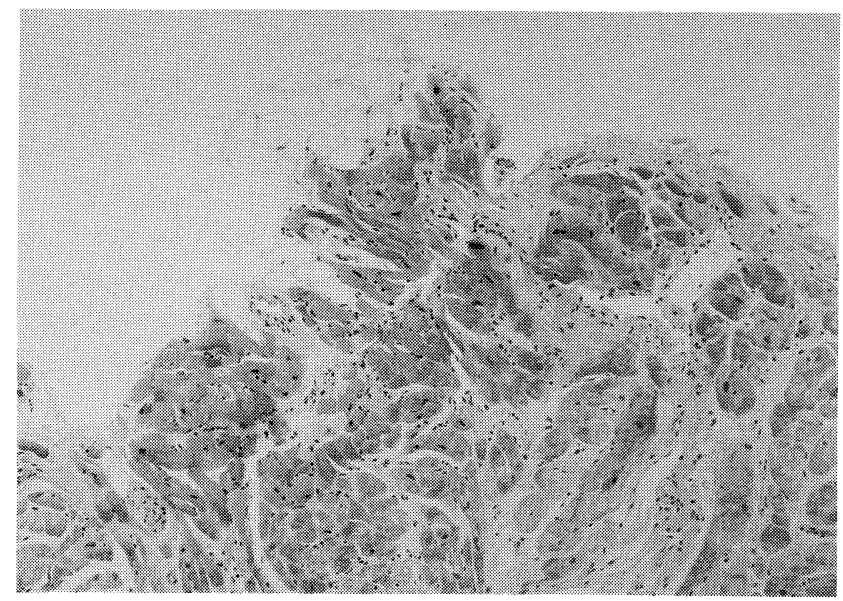

Figure 2. A biopsy of the right ventricle in case 2 showed hypertrophic and loosely associated cardiac muscle fibers and diffuse interstitial fibrosis (HE stain, $\times \mathbf{4 0 0}$ ).

because of exertional dyspnea of 1-month duration. He had no history of hypertension, but cardiac hypertrophy had been diagnosed in his father and 3 siblings, and one of the siblings died suddenly. Atrial fibrillation and heart failure were detected in Case 3 when he was 47-years-old. At the age of 48, he was admitted to a local community hospital with a cerebral infarction, and acromegaly in association with a pituitary adenoma was diagnosed. However, the patient was not considered a good surgical candidate because of his impaired cardiac function. He has been treated with $10 \mathrm{mg}$ daily of bromocriptine mesilate for 
10 years. Electrocardiography performed on admission to our hospital revealed atrial fibrillation with a rapid ventricular rate and complete right bundle branch block. A chest X-ray showed a CTR of $75 \%$ and pulmonary congestion. Serum levels of GH and IGF-I were $20 \mathrm{ng} / \mathrm{ml}$ and $473 \mathrm{ng} / \mathrm{ml}$, respectively. An echocardiogram showed a markedly dilated left atrium and left ventricular cavity with diffuse hypokinesis and a moderate amount of pericardial effusion. Echocardiographic parameters were as follows: LAD: $77 \mathrm{~mm}$, LVDd: $72 \mathrm{~mm}$, LVDs: $61 \mathrm{~mm}$, FS: 15\%, and LVM: 237 g (Fig. 4). On pulsed Doppler exami-
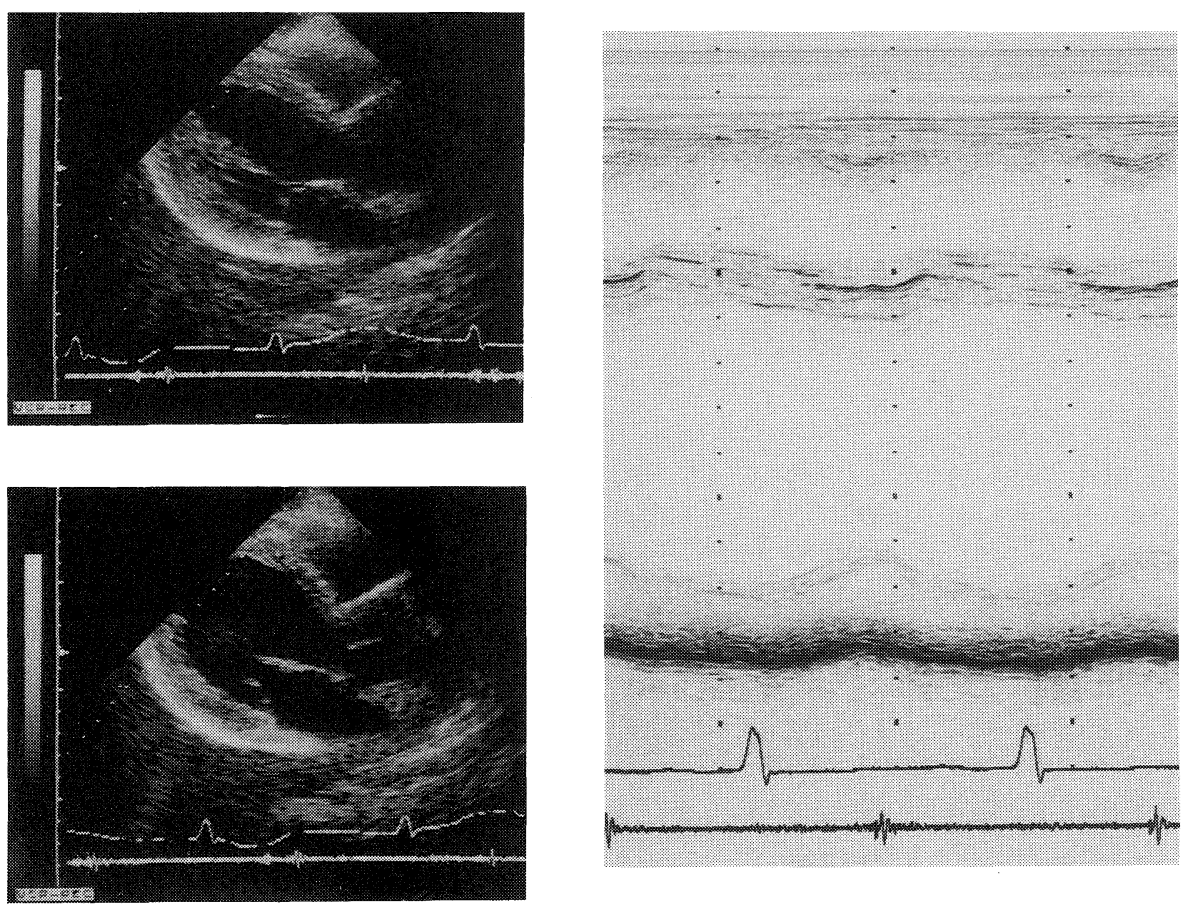

Figure 3. Echocardiographic findings in case 2.
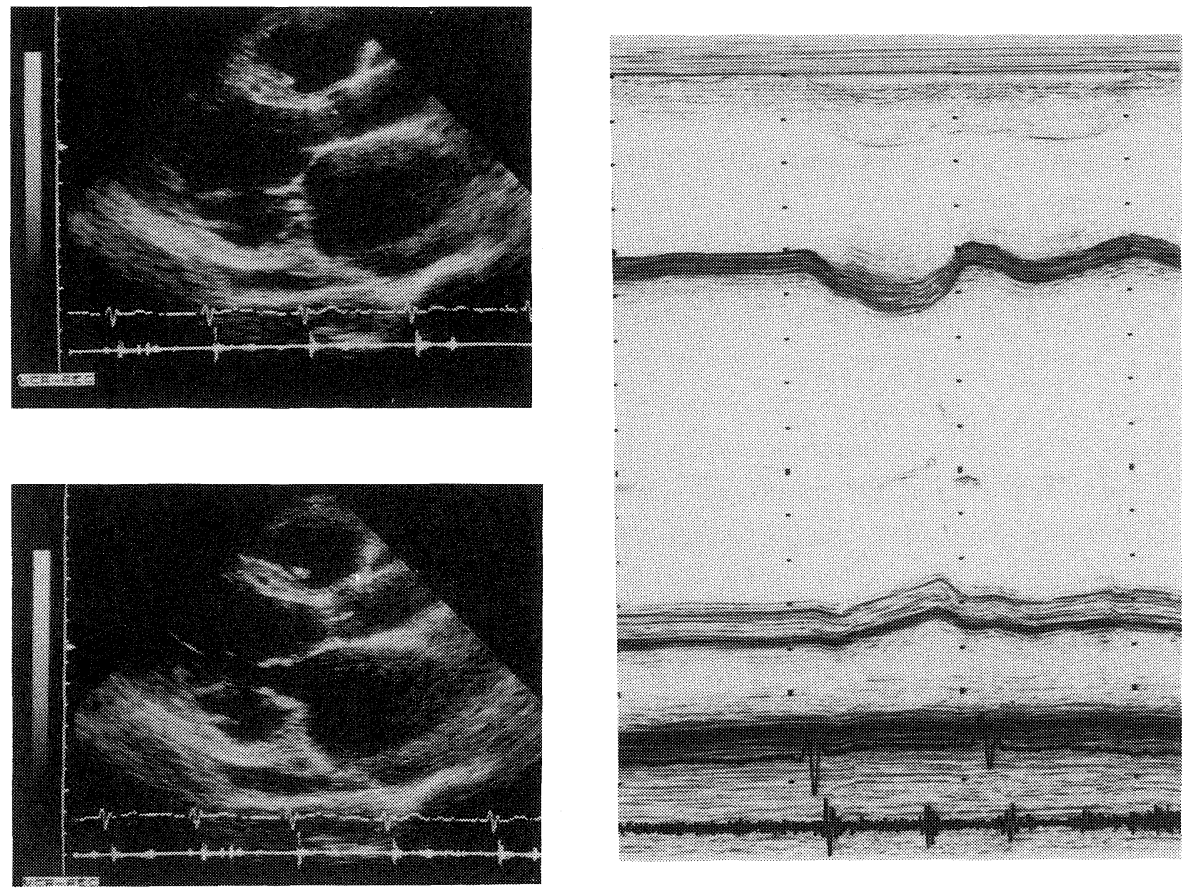

Figure 4. Echocardiographic findings in case 3. 
Aono et al

Table 1. Clinical Findings of the Present Cases

\begin{tabular}{|c|c|c|c|c|c|c|c|}
\hline \multirow{2}{*}{ Case } & \multicolumn{2}{|c|}{ Acromegaly } & \multicolumn{5}{|c|}{ Echocardiographic findings } \\
\hline & Duration (yr) & $\mathrm{GH}(\mathrm{ng} / \mathrm{ml})$ & LVDd (mm) & LVDs (mm) & $\mathrm{WT}(\mathrm{mm})$ & $\operatorname{LVM}(\mathrm{g})$ & $\mathrm{FS}(\%)$ \\
\hline 1 & 15 & 26 & 78 & 67 & 11 & 226 & 14 \\
\hline 2 & 10 & 87 & 67 & 54 & 13 & 206 & 19 \\
\hline 3 & 10 & 20 & 72 & 61 & 15 & 237 & 15 \\
\hline
\end{tabular}

GH: serum level of growth hormone, LVDd: diastolic left ventricular diameter, LVDs: systolic left ventricular diameter, WT: left ventricular wall thickness $=$ (thickness of intraventricular septum + posterior wall)/2, LVM: left ventricular mass, FS: fractional shortening.

nation, $\mathrm{PFV}$ was decreased to $55 \mathrm{~cm} / \mathrm{sec}, \mathrm{A} / \mathrm{E}$ ratio could not be evaluated because of atrial fibrillation. Treatment with conventional therapy for congestive heart failure resulted in an improvement from New York Heart Association (NYHA) class III to class II and a decrease in pericardial effusion. He was discharged on hospital day 35. Though diuretics, vasodilators, cardiotonic drugs and ACE-I were administrated after discharge, he repeatedly developed exertional dyspnea and pulmonary congestion on chest $\mathrm{X}$-ray. He was readmitted 8 months after discharge. It was difficult to control his heart failure.

Clinical findings of the present cases are summarized in Table 1.

\section{Discussion}

Cardiovascular abnormalities are common in patients with acromegaly, and congestive heart failure is an important cause of death in these patients $(5,6)$. Echocardiography has shown an increased cardiac mass, cardiac hypertrophy, left ventricular dilatation, and impaired left ventricular function in patients with acromegaly $(7,8)$. These cardiac abnormalities have been attributed to existing hypertension or coronary artery disease. However, congestive heart failure or left ventricular dysfunction occurs in 20 to $30 \%$ of patients with acromegaly who do not have hypertension or coronary artery disease, these abnormalities have been described as "acromegalic cardiomyopathy". The etiology of the acromegalic cardiomyopathy has not been clarified, but proposed etiologic factors include an increased work demand associated with generalized organomegaly and the direct effect of GH on the myocardium (9). The effects of $\mathrm{GH}$ on protein synthesis and collagen synthesis may lead to myocardial hypertrophy and interstitial fibrosis, respectively (10). Thus, a long-term elevation in the serum level of GH may cause cardiomegaly and left ventricular dysfunction, resulting in congestive heart failure. Cases 1 and 2 in the present report did not have hypertension or evidence of coronary artery disease, suggesting that their cardiac abnormalities represented acromegalic cardiomyopathy. The hypertrophy of cardiac muscle fibers and diffuse interstitial fibrosis in Case 1 may have been related to the effects of $\mathrm{GH}$ on protein and collagen synthesis.

Recent reports on echocardiographic findings in patients with acromegaly have described the following: 1) left ventricular dilatation and hypertrophy, 2) well-preserved systolic function of the left ventricle in a majority patients, followed by impaired systolic function in the advanced stage of the disease, and 3) enlargement of the left atrium in hormonally active patients (11-13). The common echocardiographic in the present three cases are: 1) enlargement of the left atrium, 2) markedly dilated left ventricular cavity with diffuse hypokinesis, 3) decrease of indices of the left ventricular systolic function (FS and PFV). However, there was no evidence of left ventricular hypertrophy. These findings are similar to those of idiopathic dilated cardiomyopathy (DCM). Echocardiographic findings in the advanced stage of acromegaly with congestive heart failure have been considered to resemble those of DCM, possibly due to diffuse interstitial fibrosis related to the effects of $\mathrm{GH}$ on protein and collagen synthesis.

Several authors have described diastolic filling abnormality or left ventricular diastolic dysfunction in acromegalic patients (14-16). We assessed the transmitral inflow velocity pattern on Doppler examination in case 1 and case 2. In case 1 , echocardiogram showed markedly dilated left atrium and left ventricular cavity with diffuse hypokinesis, suggesting left ventricular diastolic function as well as systolic dysfunction. However, the transmitral inflow velocity pattern on the pulsed Doppler examination demonstrated a normal pattern (A/E ratio $<1.0)$. Pseudonormalization of the $\mathrm{A} / \mathrm{E}$ ratio due to elevation of LVEDP can be excluded as the pressure value of the cardiac catheterization was normal. Concerning the relation between the left atrium and acromegaly, Hradec et al (11) suggested that the effect of GH on the atrial myocardium may cause significant enlargement of the left atrium. We surmised that the effect of $\mathrm{GH}$ on the atrial myocardium caused atrial systolic dysfunction, resulting in the decrease of $A$ and the normal transmitral inflow velocity pattern $(\mathrm{A} / \mathrm{E}$ ratio $<1.0)$ shown in case 1 .

Conversely, the $\mathrm{A} / \mathrm{E}$ ratio was shown to be more than 1.0 in case 2. It was suggested that left atrial function remained in case 2 , compensating for the left ventricular diastolic dysfunction. Case 3 had a family history of cardiac hypertrophy and 


\section{Heart Failure with Acromegaly}

sudden death. In addition, atrial fibrillation preceded the appearance of acromegaly. Therefore the cardiac abnormalities in Case 3 may have been due to acromegalic cardiomyopathy complicated with familiar hypertrophic cardiomyopathy. This patient's persistently elevated serum level of GH contributed to the progression of hypertrophic cardiomyopathy to the dilatation phase.

\section{References}

1) Martin JB, Kerber RE, Sherman BM, Marcus ML, Ehrhardt JC. Cardiac size and function in acromegaly. Circulation 56: 863, 1977.

2) Mather HM, Boyd MJ, Jenkins JS. Heart size and function in acromegaly. Br Heart J 41: 697, 1979.

3) Courville C, Mason VR. The heart in acromegaly. Arch Intern Med 61: 704, 1938.

4) Pepine CJ, Aloia J. Heart muscle disease in acromegaly. Am J Med 48: $530,1970$.

5) McGuffin WL, Sherman BM, Roth J, et al. Acromegaly and cardiovascular disorders. Ann Int Med 81: 11, 1974.

6) Hejtmancik MR, Bradfield JY, Herrman GR. Acromegaly and the heart: A clinical and pathological study. Ann Intern Med 34: 1445, 1951.
7) Savage DD, Henry WL, Eastman RC, Borer JS, Gorden P. Echocardiographic assessment of cardiac anatomy and function in acromegalic patients. Am J Med 67: 823, 1979.

8) Hamwi GJ, Skillman TG, Tufts KC. Acromegaly. Am J Med 29: 690, 1960.

9) Hirsch EZ, Sloman JG, Martin FIR. Cardiac function in acromegaly. Am J Med Sci 257: 1, 1969.

10) Smallridge RC, Rajfer S, Davia J, Schaaf M. Acromegaly and the Heart. An echocardiographic study. Am J Med 66: 22, 1979.

11) Hradec J, Marek J, Kral J, Janota T, Poloniecki J, Malik M. Long-term echocardiographic follow-up acromegalic heart disease. Am J Cardiol 72: 205, 1993.

12) Rodrigues EA, Caruana MP, Lahiri A, Nabarro JD, Jacobs HS, Raftery EB. Subclinical cardiac dysfunction in acromegaly: evidence for a specific disease of heart muscle. Br Heart J 62: 185, 1989.

13) Iida K, Koide Y, Sugishita Y, et al. Follow-up study of the heart in acromegaly: Pre- and post-operative evaluation. Jpn J Med 29: 22, 1990.

14) Bertoni PD, Morandi G. Impaired left ventricular diastolic function in acromegaly: An echocardiographic study. Acta Cardiol 42: 1, 1987.

15) Sacca L, Cittadini A, Fazio S. Growth hormone and the heart. Endocr Rev 15: 555, 1994.

16) Merola B, Cittadini A, Colao A, et al. Chronic treatment with the somatostatin analog octreotide improves cardiac abnormalities in acromegaly. J Clin Endocrinol Metab 77: 790, 1993. 